\title{
SALVAR LA REVOLUCIÓN Problemas para pensar la revolución en la posmodernidad a la luz de la obra de Gianni Vattimo
}

\author{
SAVE THE REVOLUTION \\ Problems thinking revolution in posmodernity \\ around the work of Gianni Vattimo \\ GUILLERMO RODRÍGUEZ ALONSO \\ Universitat Pompeu Fabra de Barcelona
}

\section{RESUMEN}

El presente artículo busca ahondar en la problemática que supone pensar la revolución desde el punto de vista filosófico en el marco teórico de la postmodernidad. A partir de este contexto, se aborda la obra de Gianni Vattimo en tres claves: análisis de la cuestión revolucionaria y su caducidad en el marco de la posmodernidad; imposibilidad de la revolución como acontecimiento en el «orden técnico»; necesidad de superar la condición metafísico-violenta de la revolución. En la conclusión se hará una pequeña tentativa para «salvar la revolución» en torno algunas de las propuestas teóricas más recientes.

Palabras clave: Acontecimiento, Filosofía de la Historia, Gianni Vattimo, Revolución, Postmodernidad.

\begin{abstract}
This paper aims to deep into the problematic of revolution tought across the philosophical view of postmodernity. Starting on this context, Gianni Vattimo's work is taken around three key-ideas: analysis of the revolutionary question and his caducity in the postmodernity's framework; the imposibility of revolution as an event inside the «technical order»; the need to overcome the metaphisycal and violent condition of revolution. In the last chapter, a small attempt will try to «save the revolution» around some ideas of recent theoric proposals.
\end{abstract}

Keywords: Event, Philosophy of History, Gianni Vattimo, Revolution, Postmodernity. 
Pero si uno quiere salvar la Revolución, hay que transformar la idea misma de Revolución.

Jacques Derrida

¿Qué ha sido de la revolución?. Término empleado hasta la saciedad, hoy no parece capaz ya de condensar ni dirigir discursos político-sociales. Pudiera ser que buena parte del desgaste sufrido sea resultado del empleo excesivo de este término por parte de ciertas ortodoxias y dogmatismos como referente de una mitología que paulatinamente la ha ido vaciando de contenido. También ha sido, no cabe dudarlo, un «horizonte de sentido» capaz de inflamar corazones de toda índole y empresas de todo cuño, alimentando así buena parte del imaginario político del siglo XX. Pese a todo, los recientes acontecimientos de rebelión y alzamiento popular no hacen sino confirmar el impasse político que se vive en el mundo occidental. No pareciera que el movimiento de los indignados: 15-M español, Occupy Wall Street, o el todavía incipiente NuitDebout francés, puedan concebirse bajo el horizonte de una «revolución»-término sobre el que apenas ha gravitado el discurso asambleario- al menos si atendemos a su concepción marxista como «salto entre eras» o la aristotélica como «cambio de régimen». Pero el problema surge cuando ni siquiera podemos concebir estos movimientos como «revoluciones fallidas», toda vez que se resisten a circunscribirse en la lógica ortodoxa del materialismo histórico. No se trata tampoco de revisitar la clásica contienda entre reformismo o revolución. En el sensus comunis se homologa la imposibilidad de alternativas al triunfo (fáctico y teórico) de la democracia neoliberal capitalista, especialmente ahora que la «era de los bloques» ha pasado. La hegemonía del capitalismo como «único sistema posible» -en su forma «democrática»- esto es, como cénit del modelo ideal de organización política y social al que todos los estados deben tender de forma progresiva - se ha ido imponiendo en el imaginario global. «iEl capitalismo es la única utopía!» exclama el filósofo Slavoj Žižek. Siendo así...«¿Podemos decir que hoy la propia idea de una transformación radical y profunda, en nuestra vida personal y sobre todo en la sociedad, ya no es pensable? ¿Y que quizás ésta no es sólo una condición específica de los últimos tiempos modernos sino que revela el carácter mitológico e ideológico de la idea misma de revolución? ${ }^{1}{ }$

Para entender por qué nos cuesta tanto pensar hoy la revolución debemos atender a dos acontecimientos clave que ya se han venido apuntando: el primero respecto al clima intelectual y político que vive europa tras la liquidación del proyecto de la Modernidad; el segundo: el fracaso del comunismo real, acontecimiento que algunos han llamado «la muerte de Marx», aludiendo a una derrota del marxismo efectuada no sólo en la praxis, sino también en el plano teórico e intelectual ${ }^{2}$. La complejidad de esta empresa -entender

1 Gianni Vattimo, Adiós a la verdad, ed. Gedisa, Barcelona, 2010, p.136.

2 Un ejemplo paradigmático de esta «crisis del marxismo» a la luz de las «sospechas» posmodernas es el emblemático ensayo de Laclau y Mouffe: Hegemonía y estrategia socialista (1985). E. Laclau y C. 
la (im)posibilidad revolucionaria- también se debe al «espesor» del propio concepto, bajo el que subyacen ideas cuyo recorrido conforma la historia misma del pensamiento occidental moderno (y buena parte de sus desencantos). Cuando comenzamos a escarbar su superficie surgen pequeños tesoros ocultos: la teología escatológica, la promesa mesiánica, el problema de la temporalidad histórica (aión, kairós, kronos), la violencia, la Utopía, la idea del «hombre», la emancipación, el destino... y sobre (o bajo) todos ellos, el problema mismo del acontecimiento.

Pese a que en estos tiempos parece difícil afirmar que «no ocurre nada» y que vivimos, como diría Baudrillard, una «huelga de los acontecimientos»... ¿acaso podemos hoy pensar una revolución política o social que reconfigure todos los posibles y actualice todas las potencias, quebrando así el actual estado de cosas? ¿Acaso cabe esperar un gran «acontecimiento» político en el marco de la progresiva tecnocratización de los estados y las instituciones supra-nacionales? En este sentido parece que la desoladora ausencia de acontecimientos (revolucionarios) nos permita rescatar aquella frase de Martin Heidegger según la cual a día de hoy «la única emergencia es la falta de emergencia» ${ }^{3}$.

En definitiva, disociar todos estos elementos que se agolpan, reacios a ser circunscritos, en torno al concepto de revolución es tarea difícil y no del todo satisfactoria. Así pues, pensemos la revolución, el acontecimiento, en torno a lo que le es propio: ser atalaya de vigilancia, nódulo, horizonte y también, quizá, un deber.

\section{LA REVOLUCIÓN COMO CONCEPTO CADUCO EN LA POSMODERNIDAD}

El marco teórico de la postmodernidad supone un abandono de las posiciones «fuertes» de la filosofía de la historia (Moderna) como gran relato de legitimación de un saber totalizante y objetivo, como señaló Lyotard en su (ya) clásico estudio ${ }^{4}$. Así, según el francés, las meta-narrativas esencialistas y universalistas que legitimaban una determinada visión unitaria de la «historia de la humanidad» y su telos, se han disuelto, dirimiéndose epistemológicamente en la heterogeneidad de los «juegos del lenguaje», -en alusión a Wittgestein- o en discursos retóricos dentro del «círculo hermenéutico» hecho-interpretación. Las narrativas de emancipación, basadas en el progreso de la Razón y la Libertad, llegan a su término una vez «el mundo verdadero ha devenido fábula» (Nietzsche) y el

Mouffe, Hegemonía y estrategia socialista: hacia una radicalización de la democracia, ed. Siglo XXI, Madrid, 1987.

3 Como escribía Gianni Vattimo en 2012: «La ausencia de emergencia es quizá la forma más absoluta del olvido del Ser, propio de la metafísica. Que hoy no suceda nada parece difícil de creer. Y, no obstante, tampoco las grandes crisis que hemos vivido y todavía estamos viviendo originan alguna novedad “paradigmática” en el sentido político-social». G. Vattimo, De la realidad: fines de la filosofía, ed. Herder, Barcelona, 2012, p. 141. (la cursiva es mía)

4 J.F. Lyotard (1979) : La condition postmoderne: rapport sur le savoir (Citaré la edición española: J. F. Lyotard, La condición posmoderna: informe sobre el saber, Ediciones Cátedra, Madrid,1984). 
saber mismo se revela narrativo, mitológico. Así, todo evento histórico -y más que ningún otro: la revolución- pierde el suelo firme del relato que lo dota de sentido, en tanto y cuanto el saber o la Verdad se revelan como dispositivos de una «gran máquina» de legitimación y no ya como fines últimos de una Razón histórica. Y es que en la postmodernidad la función legitimante del saber opera en torno a un sistema tecnocrático donde los expertos, los décideurs, determinan qué «jugadas» del lenguaje son válidas para cada caso. En este punto se crea un sistema de legitimación que ya no depende de las metanarrativas modernas, sino que se dirime en su propia performatividad. Además, toda ruptura o cesión contribuye a estabilizar este propio sistema, ya que... «incluso cuando cambian sus reglas y se producen innovaciones, incluso cuando sus disfunciones como las huelgas o las crisis o el paro o las revoluciones políticas pueden hacer creer en una alternativa y levantar esperanzas, no se trata más que de reajustes internos y su resultado sólo puede ser la mejora de la "vida" del sistema» ${ }^{5}$. Este orden, este sistema, es la «gran máquina» de la información, donde «cada vez más tareas serán confiadas a autómatas», y no ya a las instituciones tradicionales del saber. En definitiva, en la postmodernidad el criterio del saber deja de ser narrativo para convertirse en algo técnico.

En esta nueva condición postmoderna del saber... ¿cabe dudar de que los ideales propios de la Modernidad son objeto de una insorteable crisis? No son pocas las filosofías ${ }^{6}$ que se han centrado en desgranar el alcance de la «pérdida» que supone haber liquidado el proyecto de la Modernidad, entre quienes pretenden rescatarlo (p. ej. Habermas) y entre quienes prefieren sentarse a disfrutar del espectáculo de su perversión (p. ej. Baudrillard). Cada día se vuelve más problemático hablar de lo que significa la historia, el porvenir, el futuro, la humanidad y su destino como conceptos universales. Si alguien esgrime el antaño poderoso estandarte de la revolución, de la emancipación y de la libertad, se le toma por trasnochado e ingenuo. Este air dus temps coincide con muchos de los análisis que filósofos continentales han realizado acerca de la situación de la cultura europea tras la Gran Guerra, lo que Derrida llama la era de los fines ( del hombre, de la historia, del arte etc.). Pese a los diferentes posicionamientos teóricos, en muchos casos antagónicos, se mantiene el tono crepuscular y apocalíptico: preocupación por la «ausencia de eventos», la pérdida de sentido unívoco, la «crisis» de la razón, la pérdida del «aglutinante» etc.. En una reflexión apresurada, se podría concluir que, con el fin de la historia como meta-narrativa y la entrada en la post-historia, los acontecimientos (políticos, sociales, artísticos, filosóficos) no tienen ya lugar precisamente porque no tienen relato en el que inscribirse. Su contexto de sentido se ha disuelto, ha implosionado, y parece que sólo cabe recoger los fragmentos, como si hubiésemos sido tocados por aquel pequeño jorobado que atormentaba al pequeño Walter Benjamin: «a quien este hombrecillo mira, no pone

$5 \quad$ Ibídem, p. 30.

6 Un «estado de la cuestión» de estos debates, centrado especialmente en las figuras antitéticas de Lyotard y Habermas, puede encontrarse en: Modesto Berciano Villalibre, Debate en torno a la postmodernidad, ed. Síntesis, Madrid, 1999. 
atención ni en si mismo ni tampoco en el hombrecillo. Se encuentra sobresaltado ante un montón de pedazos» ${ }^{7}$.

El clima en torno a este debate sobre el fin del relato histórico se vió reavivado en torno al año 1989, con la caída del muro y el desmantelamiento de la Unión Soviética. Será en este momento cuando lo que hasta ahora entonces había sido un debate intelectual europeo se extienda al panorama mundial con la publicación del controvertido libro de Francis Fukuyama ${ }^{8}$ : El fin de la historia y el último hombre (1992). Como es sabido, el filósofo norteamericano de origen japonés se basa en la interpretación de Kojéve de la dialéctica del amo y el esclavo hegeliana para postular el «fin de la historia» como el fin de la lucha por el reconocimiento (thymos) en el triunfo de la democracia liberal capitalista: el sistema que mejor garantiza el mayor caudal de reconocimiento mutuo. Por tanto, el telos de la historia supone consumar el modelo de este «estado ideal» al que toda la humanidad debe tender. Así, en el hipotético fin de la historia, la dynamis dialéctica (de la cual la revolución era motor fundamental) habría dirimido ya todas las contradicciones inherentes (ideales o materiales) en el decurso histórico y nos hallaríamos en el remanso de la post-historia: mundo sin conflicto, sin fricción, sin eventos... sin revolución.

Tan sólo un año después de esta publicación, dos notables réplicas vendrán de la mano de Derrida y Baudrillard, con Espectros de Marx (1993) y La ilusión del fin: la huelga de los eventos, (1993) respectivamente. En ambos libros, los autores franceses rebaten las contradicciones teóricas y los intereses neoliberal-cristianos (Derrida) de Fukuyama. Para Baudrillard ${ }^{9}$, el fin de la historia es más bien su disolución, fin sin final, su aceleración o su deceleración en el tiempo sin tiempo del simulacro y lo hiperreal. La historia no ha terminado sino que en un determinado momento ha dejado de ser «real», por lo cual se nos niega incluso la experiencia del final. Para Derrida ${ }^{10}$, en un tono menos apocalíptico, el fin de la historia es producto de un tiempo que, como ya indicara el Hamlet de Shakespeare, se halla out of joint ( fuera de quicio). Así, mientras la escatología judía promete el acontecimiento mesiánico como advenimiento de un futuro salvífico, para el cristianismo el acontecimiento «ya ha sido»: la venida del mesías-cristo, por lo cual vivimos a la espera del fin, huérfanos del elemento de promesa que ofrece la teología judía. No debemos olvidar que en ambos casos la deudora de esta concepción teleológica y escatológica del tiempo es la dialéctica hegelomarxista, ya sea en su telos en el acontecimiento de la revolución y la posterior sociedad sin clases en Marx o en el advenimiento del Espíritu Absoluto autoconsciente en Hegel. Como decía Benjamin ${ }^{11}$, la teología es el feo enano quien bajo la mesa mueve los hilos del armazón del materialismo histórico.

7 W. Benjamin, Infancia en Berlín hacia 1900, ed. Alfuaguara, Madrid, 1982.

8 F. Fukuyama, El fin de la historia y el último hombre, ed. Planeta, Barcelona, 1992.

9 J. Baudrillard, La ilusión del fin: La huelga de los acontecimientos, ed. Anagrama, Barcelona, 1993.

10 J. Derrida, Espectros de Marx, ed. Trotta, Madrid, 1995, p. 77 y ss.

11 W. Benjamin, Tesis para una filosofía de la historia, (Tesis I) en: W. Benjamin, Discursos Interrumpidos I. Filosofía del arte y de la historia, Editorial Taurus, Buenos Aires, 1989, p.111. 
En el debate en torno a estas cuestiones emerge continuamente el problema de la revolución como acontecimiento («el único digno de tal nombre» dirá Derrida). Para arrojar algo de luz, espero, sobre los «interdictos» que pesan hoy sobre todo acontecer revolucionario -tanto en su facticidad (por el dominio técnico) como en su teorización (en el pensamiento posmetafísico y postmoderno)- acudiré a la obra del filósofo italiano Gianni Vattimo, quien en los últimos años ha desarrollado un singular pensamiento filosófico que, como era de esperar, no es ajeno al problema que aquí tratamos de abordar: la (im)posibilidad de la revolución, su (im)pertinencia y su (sin)sentido para el presente. Como veremos, para Vattimo la revolución se presenta no sólo como un imposible (toda vez que la postmodernidad liquida el sentido unitario de la Historia y el orden técnológico nos sume en la a-temporalidad misma) sino también como profundamente anclada en la tradición metafísica del pensamiento con la que quiere romper la filosofía pos-metafísica a partir de Heidegger. En la conclusión, trataré de hacerme eco del llamado de Derrida a «salvar la revolución», atendiendo a algunas voces que, desde la «medianoche del siglo» pasado y los albores del nuestro, nos invitan a repensarla.

\section{LA TEORÍA POSMODERNA DE VATTIMO}

Gianni Vattimo fue uno de los teóricos que, en la década de los 80, acogió fervientemente el concepto de la postmodernidad en la filosofía. Tal es así, que todavía hoy considera esta categoría como central en su análisis histórico-filosófico, impávido ante el desgaste que el propio término ha sufrido. En 1985, seis años después que La condition postmoderne, escribe el italiano El Fin de la Modernidad: nihilismo y hermenéutica en la era posmoderna, libro en el que se encuentran ya dibujados algunos de los rasgos fundamentales de toda su filosofía posterior. Para el italiano, el concepto de pos- tiene que ver con su singular interpretación de Nietzsche y Heidegger ya que será a través de la interpretación conjunta de ambos filósofos que trate de describir el estadio específico en el que se encuentra la historia del pensamiento una vez la Modernidad ha llegado a su fin. Para Vattimo...

(...) la Modernidad se puede caracterizar como un fenómeno dominado por la idea de la historia del pensamiento entendida como una progresiva «iluminación» que se desarrolla sobre la base de un proceso cada vez más pleno de apropiación y reapropiación de los«fundamentos», los cuales a menudo se conciben como «orígenes», de suerte que las revoluciones, teóricas y prácticas, de la historia occidental se presentan y se legitiman por lo común como recuperaciones, renacimientos, retornos ${ }^{12}$.

12 G.Vattimo, El fin de la modernidad: nihilismo y hermenéutica en la cultura posmoderna, ed. Gedisa, Barcelona, 1995, p.10. 
Estos fundamentos ( rund) o valores son aquellos que la crítica nietzscheana y heideggeriana revelarán como estructuras vacías y que Vattimo identifica con la tradición «metafísica». La muerte de Dios es también la muerte de todos los valores supremos y, por tanto, de los relatos que se sustentaban en ellos: progreso, emancipación, salvación; lo cual constituía el repertorio de la filosofía moderna, especialmente tras la Ilustración. De este modo, « la idea de "superación”, que tanta importancia tiene en toda la filosofía moderna, concibe el curso del pensamiento como un desarrollo progresivo en el cual lo nuevo se identifica con lo valioso en virtud de la recuperación y de la apropiación del fundamento-origen ${ }^{13}{ }$. La post-modernidad es, por lo tanto, la ruptura de esta idea de progreso continuo de la razón, predominante en el XVIII y el XIX, basado en una cierta idea secularizada de la diacronía escatológica de la historia. Sin embargo, la lógica de la postmodernidad impide situarla como una era post-erior a la Modernidad, ya que es precisamente esta noción de historicidad progresiva lo que la filosofía de Nietzsche y Heidegger ponen en tela de juicio. Por tanto, y retomando el término de Arnold Gehlen, la postmodernidad se sitúa en la post-historia, toda vez que ha terminado con la lógica de la «superación», que constituía el mito del progreso moderno, en la disolución de la categoría del novum. El fin de la historia sería para Vattimo «más bien el fin de la historicidad»: la pérdida de una determinada filosofía de la historia que, privada de sus fundamentos metafísicos, impide entender la idea de una historia como proceso universal, unitario y homogéneo. Es en este sentido que Vattimo denuncia las «teodiceas históricas» del hegelomarxismo y el sistema dialéctico, que ofrecen siempre una visión de la historia como cumplimiento de un fin último -ya sea éste la sociedad sin clases o el espíritu absolutocomo eminentemente metafísicas y caducas.

Para Vattimo, lo que denominamos «ocaso de occidente» o «era de los fines» (fin de la historia, del arte, del hombre, de las ideologías, de la moral etc.) y que constituye el ambiente intelectual de la filosofía europea desde el fin de la Guerra, es producto, en última instancia, de aquello que Heidegger llamó el «fin de la metafísica» ${ }^{14}$. Para el alemán esto significaba, primero: que la ontología es «historia del Ser», esto es, de las distintas formas en las que se ha pensado el problema del Ser a lo largo de toda la historia de la filosofía occidental, y segundo: que ésta habría llegado a su etapa final en el agotamiento de cierta interpretación del Ser. El nihilismo inherente al «espíritu socrático» que ya denunciaba nietzsche es el que ha ido vaciando la noción de Ser hasta que de él ya no queda nada. En Ser y Tiempo, Heidegger ${ }^{15}$ denuncia que la historia de la metafísica ha sido precisamente la historia del olvido del Ser en la indiferenciación entre Ser y ente (el olvido de la

13 Ibídem, p.11.

14 Véase: G.Vattimo, Introducción a Heidegger, ed. Gedisa, Barcelona, 2006. p. 52 y ss.

15 Como es bien sabido, la filosofía de Heidegger es un intento de repensar el olvido de la diferencia ontológica entre Ser y ente, rasgo caracterísitico de la Metafísica (la filosofía desde Platón hasta Nietzsche). Según el alemán, este pensamiento metafísico ha confundido el Ser en la identificación con la mera presencia de lo ente, esto es, que aquello que propiamente es no es sino aquello que se presenta al Dasein como estabilidad y constancia del ente en su presenciarse. El Ser, para Heidegger, no puede 
diferencia ontológica). Así, desde Platón se habría pensado el Ser como sinónimo de la presencia en el espacio y el tiempo del ente (lo que es, es aquello que se presenta estable, unívoco en el tiempo) cuando en realidad se olvida que el Ser es una donación que se hace al ente: un «evento». Vattimo recoge esta noción para formular que el fin de la metafísica es, por lo tanto, la postmodernidad como estadio último de un pensamiento que ha llegado al término de la interpretación del Ser como presencia, y donde sólo puede pensarse ya como «evento». De este modo, el fin de la metafísica llega cuando aquellas estructuras estables del Ser como fundamento ( grund) se revelan inestables, históricas, contingentes. Así, la era posmoderna es propiamente una era posmetafísica.

Para habitar esta stazione termini de la historia del Ser, que no es «superación» dialéctica de la anterior sino más bien etapa última en su agotamiento (Dios ha muerto pero habitaremos su cadáver largo tiempo, como decía Nietzsche) Vattimo nos propone una ontología hermenéutica o nihilismo activo, lo que en el desarrollo posterior de su filosofía tomaría el nombre de pensiero debole: un pensamiento post-metafísico y post-moderno que busca «debilitar las estructuras estables del Ser» con que la tradición metafísica lo ha ido atribuyendo. Un pensamiento no basado en el fundamento ( $g r u n d$ ) sino en su misma ausencia (abgrund, abismo) es decir, en el nihilismo. Es precisamente en el fin de la metafísica entendida como último estadio de la Historia del Ser heideggeriana donde residen nuestras esperanzas de crear un pensamiento post-metafísico y post-histórico, que no dependa de los relatos y fundamentos de una Modernidad caduca.

En este contexto, identificando la postmodernidad como fin de los valores en su «deconstrucción» nihilista, el concepto de Historia pierde su sentido como relato homogéneo, como elemento vertebrador, unitario y como vector del progreso de la Razón y la Libertad. Una vez se ha «disuelto» o «liquidado» la noción de historicidad que se forjó en la filosofía del XIX, pensar la revolución se vuelve problemático, en tanto era parte fundamental y constitutiva de la misma mitología de la Modernidad. Vattimo se cuestiona...

\begin{abstract}
¿Qué significado tiene hoy la tesis según la cual«no hay más historia» $\mathrm{y}$ «nada más puede suceder»? (...) No sé si tal situación puede llamarse el final de la Historia en el sentido de Fukuyama (1992), sobre todo porque las cosas siguen adelante y lo que parece estar excluido es sólo lo que más deseamos: la conversión, la catástrofe, la revolución. ${ }^{16}$
\end{abstract}

Nótese que Vattimo concede a la revolución tanto el carácter de acontecimiento político y social como de evento individual y espiritual. En Adiós a la verdad (2009) llamará a estas dos dimensiones «catástrofe» y «conversión», respectivamente. La imposibilidad, tanto de la revolución interior -en la figura de la conversión religiosa- como

reducirse únicamente a esta dimensión, puesto que es un elemento que se sustrae y se otorga en un continuo movimiento de donación. El ser no es, sino que acontece. 
de la social en forma de acontecimiento catastrófico (la revolución como catástrofe, mas no en sentido peyorativo, sino como ruptura, acontecimiento que lo trastoca todo) es una consecuencia directa de la disolución del sentido unitario de la historia como metanarrativa de legitimación, pero también de la no-historicidad que ya Heidegger denunciaba en el pensar «calculante» de la técnica. Aquí se introduce el orden de lo técnico como uno de los principales escollos del acontecer revolucionario.

\section{EL ORDEN TÉCNICO}

Como hemos visto, Vatimo emplea la noción heideggeriana del «fin de la metafísica» como piedra de toque de su pensamiento acerca de la posmodernidad. Pero esta era final tiene su modo específico de pensar el Ser una vez el pensamiento fundante metafísico ha llegado a su término. Esta modalidad del pensar técnico, que es el fruto más maduro del proceso de olvido de la diferencia ontológica en la metafísica de las presencias, es lo que Heidegger llama el Ge-stell. ${ }^{17}$

El Ge-stell es una noción compleja de la constelación del pensamiento Heideggeriano, que en una primera acepción significa el acto de emplazar (stellen) algo en un marco ${ }^{18}$. Este tipo de pensamiento «emplazante» es el resultado del modo (metafísico) de concebir el Ser como mera presencia del ente, debido a que supone pensar éste como objeto a disposición del uso técnico. Así, todo ente se piensa ya dentro de una trama de causalidades y efectos propios del pensar científico y tecnológico. Este marco de pensamiento supone la realización última del ideal racional y científico que dispone en abstracto todos elementos del mundo como una red inter-conectada de objetos manipulables y disponibles para su transformación como meros recursos o útiles. Este modo de hacer comparecer los entes en el seno de una relación técnica emplazante es lo que Heidegger llama Ge-stell y que constituye además la esencia misma de la técnica. No se aleja mucho del pathos epocal de sospecha ante la dimensión deshumanizante de la técnica y que puede intuirse también en nociones como la de «razón instrumental» de Adorno y Horkheimer ( no casualmente el propio Vattimo compara a menudo el Ge-stell de Heidegger con el «mundo totalmente administrado» que estos autores teorizan y denuncian). En este sentido, metafísica e iluminismo son dos caras de un mismo proyecto de búsqueda de Verdad en torno al «aseguramiento» de lo ente como presencia. Si el orden técnico es el pensamiento del Ser propio al estadio final de la metafísica -allí donde la razón calculante basada en el

17 Heidegger introduce esta noción en la famosa conferencia La pregunta por la técnica (Die Frage nach der Technik) y en algunas de sus obras tardías. Véase: M. Heidegger: "La pregunta por la técnica", trad. de Adolfo P. Carpio, Época de Filosofía, vol.1, nº1, 1985, p. 7-29. y M. Heidegger, Identidad y diferencia, ed. Anthropos, Barcelona, 2008

18 Un análisis detallado del término y sus posibles traducciones se da en: G.Vattimo, Las aventuras de la diferencia: pensar después de Nietzsche y Heidegger, ed. Península, Barcelona, 2002, p.231 y ss. Recojo aquí las traducciones al castellano que emplea Vattimo en acuerdo con sus traductores. 
pensamiento del «disponer» propio de la confusión entre ente y Ser ha triunfado- este es también producto del olvido del Ser en su presenciarse: en su disposición a ser requerido por el uso y la función misma. Se alumbra así un mundo donde todo encaja, cada pieza se sitúa diligentemente en su sitio y «todo funciona». Esta, nos recuerda Vattimo, es la forma más refinada que la metafísica ha alcanzado en su pensamiento del Ser como presencia, como datidad estable del ente, posibilitando así las filosofías realistas sobre las que la ciencia obtiene su legitimación.

En definitiva, toda vez que la tecnología impone el pensar-instrumental del Ser como presencia objetiva y datible del ente, nos hallamos en la culminación del pensamiento fundante y metafísico y también, simultáneamente, en el primer paso para su superación, como veremos. Este tipo de pensamiento técnico, según Vattimo, el principal causante de la imposibilidad de que acontezca el Ser y, por consiguiente, la revolución, en sus dos dimensiones (conversión y catástrofe). Este tránsito de una metafísica realista de las presencias a una política autoritaria es uno de los rasgos que define la época actual de impasse filosófico-político denunciado por la teoría de Vattimo. De este modo...

\begin{abstract}
... la experiencia de conclusión que tenemos en nuestro tiempo, tanto a nivel de acción política como a nivel de proyectos teóricos (pensad en la desaparición del pensamiento utópico), es un síntoma del final de la metafísica. La metafísica, como podréis recordar, termina en el dominio universal de la técnica, que hace realidad el sueño metafísico de la organización universal de todos los seres dentro de la estructura cada vez más previsible de causas y efectos. El sueño todavía no se ha realizado por completo, como es natural, y esto podría describirse como el largo adiós del Dios muerto del que hablaba Nietzsche. En línea de principio, sin embargo, el orden científico-tecnológico ya es real, en especial en términos sociales y políticos. Lo que parece ser más imposible en nuestro mundo es un cambio radical, aunque sólo fuera en la dimensión local de la Revolución francesa, ni que hablar de la Revolución rusa de 1917. Heidegger define el orden técnico en el que vivimos como el Ge-stell, enframed, (...) para definir la condición de estar capturados en una red de la que es imposible huir". ${ }^{19}$
\end{abstract}

Por tanto, estamos «capturados», en esa red que la metafísica-como cumplimiento de la técnica en la organización total de los entes- ha creado: un mundo donde «todo funciona» y la emergencia de alternativas, cambios y acontecimientos pertenece a lo oculto, es decir, a lo que se esconde tras el Ser toda vez que se lo dispone (stellt) como presencia. Lo impensado del Ser se halla así tras lo que se ofrece y dispone en el pensamiento calculador y objetivo de la metafísica, negando su carácter eventual. De ahí la dificultad que tiene el acontecimiento de producirse, puesto que está «atrapado» en esta red de disposiciones técnicas donde nada es imprevisto, donde todo cae dentro del tablero, del marco de actuación impuesto. Así como la precisión de las tecnologías de predicción imposibilitan

19 Vattimo, Adiós a la verdad, op.cit. p.133 y ss. 
la catástrofe, la identificación entre noticia y evento que proponen los mass-media dotan al paso del tiempo de una ligereza a-histórica ${ }^{20}$, e impiden el acontecimiento mismo. En el «imperio de la previsibilidad», donde todo es programado en su previo acontecer, ya nada puede ocurrir ${ }^{21}$. Como dice Baudrillard: no es que nada pueda suceder, es que todo ha sucedido ya.

Vattimo, en sus últimas investigaciones junto a Santiago Zabala ${ }^{22}$, recurre continuamente a la piedra de toque de la «falta de emergencia» heideggeriana para explicar el impasse político, social y cultural en el que nos encontramos por medio de la «falta de acontecibilidad» del mundo «totalmente administrado», el cual anula todo conflicto de interpretaciones en la objetividad de los criterios técnicos. Esto tiene su traducción política en la preocupación creciente ante la progresiva tecnificación de los aparatos políticos y la pérdida de soberanía popular en favor de los tecnócratas. Sin embargo no se pretende dar una visión denostada de la tecnología ni del pensamiento científico. Al contrario, Vattimo siempre nos recuerda que en la disolución-oscilación que opera dentro del Ge-stell se hallan también nuestras esperanzas de emancipación, puesto que es precisamente ahí, en el marco del pensamiento técnico, donde se diluyen los atributos con que la metafísica ha ido atribuyendo al Ser, en especial propiciando la confusión entre sujeto-objeto, piedra nuclear de la metafísica. El pensar técnico, al objetivar todo ente en su «disponibilidad» destruye el eje metafísico de la subjetividad; nos hace «oscilar» en una reificación total y , por tanto, es a la vez salvación y condena de la misma metafísica. Como se cuida Heidegger de señalar, en palabras de Hölderlin: «Cercano está el Dios, pero difícil es captarlo; y donde crece el peligro, crece también lo que nos salva». ${ }^{23}$

No quisiera extenderme en las consecuencias que la tecnología o el pensar técnico tienen para la imposibilidad del acontecimiento, temática que forma parte del zeitgeist de los años cuarenta en adelante y que afecta a buena parte de la intelecualidad europea: Adorno, Horkheimer, Heidegger o Günther Anders, así como teóricos más recientes (Baudrillard, Gérard Wajcman o Manuel Castells, entre muchos otros) constituyendo de este modo uno de los grandes «debates del siglo» cuyo frente no hace sino ensancharse.

20 Temas que trata Vattimo en La societá transparente (G. Vattimo, La sociedad transparente, ed. Paidós, Barcelona, 1990) y que se puede resumir en aquella otra frase de A. Gehlen por la cual, mediante las tecnologías informacionales, «la historia se ha convertido en routine». (Véase el primer capítulo de El fin de la Modernidad, op.cit.)

21 Lo expresa magníficamente Baudrillard : «¿Qué tenemos que hacer cuando realmente nada llega a su fin, es decir, cuando nada ocurre realmente, ya que todo está calculado, auditado y realizado por adelantado (el simulacro precede a lo real, la información precede al acontecimiento, etc.)? Nuestro problema ya no es: ¿qué vamos a hacer con respecto a los acontecimientos reales, a la violencia real? Por el contrario, ahora es: ¿qué vamos a hacer con respecto a los acontecimientos que no tienen lugar? No: ¿qué vamos a hacer después de la orgía? Sino: ¿qué vamos a hacer cuando la orgía ya no ocurra... la orgía de la historia, la orgía de la revolución y la liberación, la orgía de la modernidad?» ( J.Baudrillard, La ilusión vital, ed. Siglo XXI, Buenos Aires, 2002. p. 33) (La cursiva es mía)

22 G. Vattimo y S. Zabala, Comunismo hermenéutico: de Heidegger a Marx, ed. Herder, Barcelona, 2012.

23 Véase: M. Heidegger, La pregunta por la técnica, op. cit. p. 28. 
Por nuestra cuenta, mantengamos el foco en que, para Vattimo, el hecho de que la revolución no pueda darse, tanto en el plano teórico como fáctico, es una de las consecuencias del fin de la metafísica como término de los relatos de la modernidad, de la historia heideggeriana del Ser y de su última fase: el Ge-stell, que es precisamente el mundo a-histórico de la técnica, un nuevo marco de pensamiento donde cohabitan simultáneamente la opresión y los «posibles» de la emancipación.

\section{METAFÍSICA Y VIOLENCIA}

Retornando al plano político, debemos considerar que la reflexión que hace Vattimo de la revolución no se realiza únicamente en torno a su (im)posibilidad sino también en torno a su conveniencia. Esta se pone en duda si partimos de una crítica de la revolución como concepto deudor de posiciones metafísicas, esto es: violentas. En tal caso: ¿Nos conviene seguir pensando la revolución habida cuenta de su condición violenta ${ }^{24}$ íntimamente relacionada con el pensamiento impositivo y dominante de la metafísica?. El proyecto filosófico del pensiero debole, en su tarea de «debilitar las estructuras estables del Ser que permiten el dominio y el ejercicio autoritario del poder» hace una identificación clara entre metafísica y violencia. De este modo, allí donde alguien esgrime lo «objetivo» $\mathrm{o}$ «constante» para fundamentar una única visión del mundo, una verdad absoluta y totalizante, se está dando una relación metafísica de dominio. Toda vez que alguien impone un relato metafísicamente fundamentado (ej. la historia como progreso) algo queda «fuera de campo», olvidado, ocultándose (como sucedía con el olvido del Ser en Heidegger) tras el relato impuesto. El lector notará que esta idea tiene resonancias en la filosofía de la historia de Walter Benjamin, desarollada especialmente en las Tesis para una filosofía de la historia. En este testamento filosófico el berlinés hace alusión a la historia olvidada de los perdedores y oprimidos que, como «ruinas», han quedado al margen del relato histórico de los vencedores. Se trata de la historia de los débiles, el discontinuum de la historia, en oposición al relato continuo y unitario de los vencedores, que genera ese tiempo «homogéneo y vacío» ${ }^{25}$. Vattimo retoma esta idea para hacer la torsión hacia una praxis filosófica, especialmente presente en sus últimas obras, en las que de un pensamiento débil se pasa a un «pensamiento de los débiles» de inspiración benjaminiana, realizando así una singular reunión entre Nietsche, Heidegger y Marx.

24 «Es posible actuar una emancipación que libre la existencia a sus aspectos de gozo inmediato, es decir, que nos aproxime la felicidad, o al menos una vida buena, sin tener que pasar por la violencia que la revolución entraña y ejerce sobre todo en los militantes revolucionarios? La esperanza en una revolución que se actúe mediante una pequeña distorsión del sentido de las mediatizaciones de nuestra vida del consumismo, de la inflación misma del valor de cambio etc - persigue encontrar y dar respuesta afirmativa a esta pregunta. Pero, ni que decir tiene, que se trata sólo de una hipótesis, y que lo pertinente es verificarla.» Vattimo, La sociedad..., op.cit. p.71 
Para embarcarnos en esta empresa, lo primero que Vattimo señala es la necesidad de superar el pensamiento dialéctico. Frente a la Aufhebung de la dialéctica hegeliana, la cual implica una Überwindung (superación-conservación) -y que seguiría en la lógica del progreso y el «dejar atrás» de la teleología- Vattimo nos propone otro término que Heidegger emplea para referise al modo de enfrentarse al fin de la metafísica: Vervindung. Esta noción remite, en vez de a la superación, a la remisión o torsión de quien se recupera lentamente de una enfermedad, pero sin recobrarse nunca del todo ${ }^{26}$. Heidegger indicó que es imposible superar la metafísica, toda vez que el propio término "superación" se mantiene en su misma lógica. «Salir de la metafísica, dice Heidegger, no es posible de un modo radical, y por eso habla de una Verwindung, de una distorsión, más que de una Überwindung, una superación» ${ }^{27}$. Por tanto la revolución no puede ser el proceso que el hegelomarxismo ortodoxo ha postulado como resolución última de los antagonismos dialécticos (como Aufhebung y Übervindung). De este modo, debe leerse Marx a través de la crítica anti-metafísica que propone Heidegger, puesto que «si siguieramos exclusivamente a Marx, volveríamos a una metafísica racionalista e historicista, en la que toca a los filósofos expresar la verdad definitiva de la historia que sólo el proletariado expropiado conoce y lleva a cabo con la revolución» ${ }^{28}$. En cambio...

...el hecho de que hoy la revolución nos parezca legible en términos de Verwindung abre un campo de lectura y de interpretación del todo legítimo. Hoy nos damos cuenta de la cercanía entre el silencio de los vencidos de Benjamin y el silencio del Ser de Heidegger. Hoy, con la finalización de la metafísica en el nihilismo del mundo mediatizado del imperialismo global, nos damos cuenta de que una revolución concebida como Überwindung no puede sino originar nuevas configuraciones metafísicas del dominio ${ }^{29}$

La revolución en la era del fin de la metafísica debiera alejarse de las lógicas que han impuesto los pensamientos dialécticos, teleológicos y totalizantes, esto es, ha de devenir «débil», hermenéutica, dialógica. La emancipación no podrá venir ya de un gran relato donde se anhele el cumplimiento de una «Verdad» ${ }^{30}$ sino que deberá partir de un

26 Para un análisis completo del significado etimológico y filosófico de Verwindung véase el capítulo « El nihilismo y lo Posmoderno en filosofía» en Vattimo, El fin de la Modernidad, op.cit. p.145 y ss.

27 Vattimo, De la realidad... op.cit. p.189.

28 Ibíd. p.199.

29 Ibíd. p.189.

30 Vattimo señala que... «Marx invita a criticar siempre la ideología (que es siempre la de la clase dominante) en nombre de una "verdad". El derecho del proletariado a hacer la revolución se basa, a fin de cuentas, en el hecho de que sólo el proletariado ve la verdad (del hombre, de la historia, e incluso de la economía: de ahí los famosos planes quinquenales de Stalin y Mao), ya que al no tener ningún interés que le ofusque la vista (y al tener sólo su propia fuerza de trabajo y reproductiva), ve como from nowhere, realiza el verdadero saber absoluto en el que pensaba Hegel. Ese derecho (revolucionario) del proletariado está fundado, pues, en su capacidad de verdad, que también es una actividad metafísica. Como si para el mismo Marx, la emancipación (digamos, la salvación) dependiera del conocimiento objetivo (no oscurecido por la ideología) de la verdad. De ahí, aunque no tan sólo, puede decirse que 
«conflicto de interpretaciones» siempre irresoluble, propio de la filosofía hermenéutica radical y nihilista que propone Vattimo. Sin embargo, renunciar a la revolución como forma violenta de imposición de una determinada verdad no es necesariamente renunciar a la emancipación. Pero «la emancipación -para Vattimo- sólo puede pensarse dentro de un entendimiento eventual del Ser, es decir, ya no se puede hablar de un pensamiento de emancipación motivado por un anhelo de completitud y definitividad. La emancipación ya no es un telos que se pueda conseguir mediante métodos de la razón científica, sino sólo como debilitamiento de las estructuras metafísicas ${ }^{31} \gg$. La emancipación no es proyecto ni relato, sino una oportunidad que se nos brinda en el final de la metafísica como proceso de debilitación de las estructuras estables del Ser, en una progresiva reducción de la violencia impositiva del dominio metafísico. Vattimo en sus últimas obras, abogará por un «comunismo hermenéutico» o «comunismo débil» que no debemos entender en el sentido «fuerte» de la tradición marxista- como un proyecto o un resultado de la razón histórica - sino como un horizonte ideal, una grieta dejada en los márgenes del «capitalismo metafísicamente emplazado ${ }^{32} \gg$; un espacio del olvido, del ocultamiento, donde todavía reside una promesa. A este respecto, la voz de Derrida en su formidable ensayo Espectros de Marx resuena con fuerza:

... se trata entonces de pensar otra historicidad - no una nueva historia ni menos aún un new historicism, sino otra apertura de la acontecibilidad como historicidad que permita no renunciar sino, por el contrario, abrir el acceso a un pensamiento afirmativo de la promesa mesiánica y emancipatoria como promesa: como promesa y no como programa o proyecto onto-teológico o teleo-escatológico ${ }^{33}$.

\section{HACIA LA(S) REVOLUCIÓN(ES) DÉBIL(ES). CONCLUSIÓN}

Pero si uno quiere salvar la Revolucion, hay que transformar la idea misma de Revolucion. Lo que esta perimido, envejecido, arrugado, lo que resulta impracticable, por mil razones, es cierto teatro revolucionario, cierto proceso de toma de poder al que en general se asocian las Revoluciones de 1789, 1848 y 1917. Creo en la Revolucion, es decir, en una interrupcion, una cesura radical en el curso ordinario de la Historia. No

deriva la tendencia del «comunismo real» (soviético, chino, etc.) a devenir régimen autoritario. Si la revolución proletaria se consuma, ya se está en el régimen de verdad, que debe ser protegido de toda herejía, de toda pretensión de cambio. Sin embargo, si se pensara en Marx liberado de estos residuos metafísicos, es posible imaginar un comunismo ideal (opuesto a los comunismos "reales")» Vattimo, Adiós a la verdad, op.cit. p. 120. (La cursiva es mía)

31 Wolfgang Sützl, Pacifismo estético en Gianni Vattimo, ed. Icaria, Barcelona, 2007, p.137.

32 Noción empleada por Vattimo y Zabala en Comunismo Hermenéutico para definir y criticar el sistema democrático neoliberal metafísicamente fundamentado, el cual actúa como modelo al que toda la humanidad debe tender de forma hegemónica y, en la gran mayoría de casos, de forma violenta. 
existe una responsabilidad etica, por otra parte, ni una decision digna de tal nombre que no sea, por esencia, revolucionaria, que no este en ruptura con un sistema de normas dominante, hasta con la idea misma de norma, y por lo tanto de un saber de la norma que dictaria o programaria la decision. Toda responsabilidad es revolucionaria, porque trata de hacer lo imposible, de interrumpir el orden de las cosas a partir de acontecimientos no programables. Una Revolucion no se programa. En cierto modo, como el unico acontecimiento digno de tal nombre, excede todo horizonte posible, todo horizonte de lo posible, por lo tanto de la potencia y el poder $^{34}$.

Como hemos visto, para el pensador italiano la revolución, si hubiera de darse, tendría que tomar la forma de una Vervindung (dis-torsión, remisión) y ya no de una $A u$ fhebung (superación/conservación) dialéctica. Esto se debe no sólo a la «incredulidad» de la posmodernidad para seguir en la lógica del decurso unitario de la historia como gran relato emancipador, sino también por la «violencia metafísica» que mantiene en su seno la visión universal y totalizante de una Verdad en cumplimiento. Una revolución bajo el signo de lo dialéctico, como subsunción de contradicciones en la superación teleológica, siempre seguirá inserta en el relato homogéneo y continuo de los «vencedores» de la historia, imponiendo una razón y un sentido (metafísico) a los acontecimientos. Sin embargo, la revolución entendida como momento de discontinuidad, interrupción ${ }^{35}$, emerger de la verdad como aletheia -en el sentido heideggeriano de develamiento, desocultación del Ser- podría ser entendida, en el marco de un conflicto hermenéutico, como aquellos remanentes de verdad que han quedado ocultos bajo el relato «oficial». Podríamos decir, pervirtiendo un poco a Benjamin, que allí donde un totalitarismo (metafísico) triunfa, se oculta una revolución fallida. Por tanto ... «¿Existe un concepto de revolución no violento, es decir, que no comporte la absolutización de un valor, de una perspectiva (...)?»

Será en una insólita reunión ${ }^{36}$ entre Nietzsche, Heidegger, Marx y Benjamin donde Vattimo busque establecer las posibilidades emancipatorias que nos ofrece el final de la

34 J. Derrida y E. Roudinesco, ¿Y mañana qué?, ed. Fondo Cultura Económica, México, 2009, p.95. (La cursiva es mía)

35 De este modo la pensaba Benjamin, véase: M. Löwy, Aviso de incendio.Una lectura de las tesis "sobre el concepto de historia”, ed. Fondo Cultura Económica, Buenos Aires, 2003.

36 Hay que decir que pese a emplear a Benjamin como uno de los inspiradores de esta tesis, este no puede «ganarse» así como así como filósofo avant la lettre del pensiero debole, puesto que, como advierte Löwy, el materialismo dialéctico de Benjamin, pese a su crítica del progreso y del relato de los vencedores, no puede entenderse en el marco de la Posmodernidad. Advierte Löwy: «La concepción de la historia de Benjamín no es posrnoderna, ante todo porque, lejos de estar "más allá de todos los relatos" -en el supuesto de que algo así sea posible-, constituye una forma heterodoxa del relato de la emancipación: inspirada en fuentes mesiánicas y marxistas, utiliza la nostalgia del pasado como método revolucionario de crítica del presente. Su pensamiento, por tanto, no es "moderno" (en el sentido habermasiano) ni "posmoderno" (en el sentido de Lyotard) y consiste, antes bien, es una "crítica moderna de la modernidad " (capitalista e industrial), inspirada en referencias culturales e históricas precapitalistas.» ( M. Löwy, op.cit. p. 14). Sin embargo, en la transición que hace Vattimo del pensamiento débil hacia el «pensamiento de los débiles», la interpretación de estos aspectos de Benjamin es crucial. Pese a todo, el italiano, honestamente, siempre advierte de la arbitrariedad de sus interpretaciones. 
metafísica. Una vez la noción de «revolución» moderna se revela demasiado «fuerte» para atender al olvido de los débiles (la diferencia, el acontecimiento del Ser), ésta ha de repensarse a fondo, especialmente si queremos conservar su potencial emancipador y sustraerla a la estrategia de la dominación.

¿Cómo construir, pues, una idea de revolución que no tenga sus ojos fijos en el telos de una «historia» universal y unitaria; en un futuro forjado en el yunque del progreso de las te(le)ologías seculares? ¿Cómo cumplir con esa revolución sin programa a la que nos exhorta Derrida? ¿Debemos acaso seguir manteniendo tan gastada palabra como un ídolo cuya faz se ha desdibujado? En mi apuesta pascaliana estoy aceptando el llamado de Derrida, quien nos propone que para salvar la (palabra) revolución debemos resignificarla por completo. Debido a esto he querido plantear la opción de Vattimo -entre muchas otras- porque me parece que se inserta en una «armonía» común al pensamiento actual que mantiene ciertas semejanzas, ciertos aromas y resonancias: un centro tonal compartido por otras ideas que, aún siendo conscientes del enorme peso muerto que nos asfixia en estas horas crepusculares, quieren ya una filosofía de la aurora.

Para encontrar, pues, un nuevo tipo de revolución puede ser útil acudir de nuevo a Benjamin. Será en una de las notas preparatorias de las Tesis para la filosofía de la historia donde éste afirme lo siguiente: «Marx dijo que las revoluciones son la locomotora de la historia mundial. Pero tal vez las cosas se presentan de muy distinta manera. Puede ser que las revoluciones sean el acto por el cual la humanidad que viaja en tren aplica los frenos de emergencia ${ }^{37}{ }$. Esto es: la revolución entendida como interrupción de un proceso catastrófico: el del tecno-capitalismo anclado en la idea del progreso. Aquí reside, en buena medida, la clave de un nuevo tipo de revolución pos-metafísica y posmoderna que propongo, tomando en cuenta las consideraciones de Vattimo. Este tipo de revolución no ya como Aufhebung dialéctica ni como resultado de una «razón histórica universal» sino precisamente como interrupción de dicho proceso: discontinuidad. Se trataría de pensar en aplicar el freno de emergencia del tren del progreso y poner palos en la rueda de esta «gran máquina» tecno-capitalista ${ }^{38}$. La metáfora de la rueda se me presenta muy sugerente. En tal caso cabe preguntarse: ¿Acaso no habría dos ruedas que se superponen: una, aquella a la que se refiere Benjamin, que se lanza hacia el precipicio sin frenos, que avanza mecánicamente en el catastrófico proceso de su propia aceleración, y otra: la rueda como circuito: ahistórica, estática y bien engrasada, representando la inmovilidad de un gran mecanismo cerrado?. Ambas ruedas pudieran ser, en el fondo, la misma rueda, pese a que resulten a primera vista incompatibles. Esto podría ser, como en la trinidad, el gran misterio: la superposición de estas dos temporalidades y de estos dos mecanismos. ¿Acaso no es como la imagen que la Física nos ha dado del planeta tierra, poseedora de

37 Este fragmento se puede leer en las anotaciones preparatorias de las Tesis, recogidas en la citada obra de M. Löwy.

38 ¿Es posible una ironía o suspicacia mayor cuando el propio término revolutio proviene precisamente del giro de la «rueda cósmica»? 
dos tipos de movimientos (rota sobre el sol, avanza, y también rota sobre si misma, en una suerte de estatismo introspectivo)?.

La superposición de una historia de los vencedores que opera, tal y como Benjamin formula, en el «tiempo homogéneo y vacío»-que es el cronos aditivo del historiador positivista- con la a-historicidad que Heidegger señaló en el orden técnico parece una contradicción difícil de reunir. Sin embargo, si algo critica Benjamin en el relato de los vencedores es precisamente la cerrazón de la historia, la incapacitación para el momento mesiánico (como kairós), el tiempo-ahora (Jetzteit) que es la «apertura revolucionaria»: donde salta el continuum de la historia y se precipita el potencial emancipador. El tiempo «cerrado» que no permite albergar en sí ya nada (el acontecimiento, el mesías) podemos compararlo con el orden técnico, el Ge-stell, que anula en su disponer (stellen) la emergencia del evento del Ser, negando la historicidad en el triunfo de un orden estable de los entes objetivos (para Vattimo, como hemos visto, el olvido de la historia de los débiles y los oprimidos de Benjamin es correlativo al olvido del Ser en la mera presencia de los entes que denuncia Heidegger.).

Ese marco de emplazamiento (Ge-stell) puede ser comparable a una gran maquinaria de relojería donde todo está en su sitio y cada pieza cumple el requerimiento de su función, del mismo modo que el encadenamiento causal de los acontecimientos «necesarios» del historicismo positivista y el materialismo científico (el gran relato de los vencedores) genera la figura de la historia como gran mecanismo dialéctico. Para ambas figuras, la revolución consiste en ser «interrupción» $\mathrm{y} / \mathrm{o}$ «freno».

Para la segunda versión de este mecanismo o rueda, aquella que no baja por el precipicio, sino que es estática como un circuito, parece que la revolución-interrupción consista -y esto es un leve matiz- más que en detener un proceso teleológico y progresivo -que, en definitiva, ya se ha revelado vacío tras el fin de los Grandes Relatos (aunque su inercia persista en la ilusión del progreso tecnológico ) - en crear espacios de ruido, esto es: recodificaciones que entorpezcan su límpido flujo informacional, el cual busca continuamente reducir la resistencia y circular sin obstáculo en la auto-transparencia total de sus redes y la infinita repetición de lo mismo. Esa total auto-transparencia-que asemeja al Espíritu Absoluto hegeliano- opera anulando la diferencia, el cambio,el espesor, la rugosidad (todo es ya-lo-mismo: espíritu auto-consciente de sí). Por tanto, en el pensamiento revolucionario se impone la siguiente pregunta: ¿Cómo crear opacidad frente a la transparencia? ¿Cómo detener la máquina de lo igual? .

Hay dos imágenes fílmicas, ya icónicas, que expresan adecuadamente el nuevo concepto revolucionario que aquí se explora. Así, mientras el obrero alienado interpretado por Chaplin en Modern Times (1936) fluye por los engranajes (fig.1) sin oponer resistencia, imitando sus formas, apretando tuercas aquí y allá -es decir: «mejorando la vida del sistema», como decía Lyotard- se trataría de ser aquel otro obrero de la Metrópolis (1927) de Fritz Lang, quien, al caer desfallecido en el Moloch-máquina, genera un pequeño instante de caos, propiciando que la máquina se detenga unos instantes antes de que todo vuelva a su cauce y permitiendo así la revelación en el joven Freder. O tal vez como el 
propio Freder, protagonista del film, intentando en vano detener aquel reloj gigante que marca el insoportable ritmo del trabajo (fig. 2). Aquí, meter palos en la rueda no significa tanto accionar el freno de emergencia, sino, como ya se ha dicho, generar espacios incodificables e inasumibles por el sistema: conflictos, ruido, diferencia. Se trata de crear nuevo código reapropiado, frente al impertérrito y mecánico avance del todo-igual. Vattimo habla de multiplicar las fricciones, luchar contra todo emplazamiento metafísico, debilitar todo pensamiento impositivo de dominación y favorecer el conflicto de interpretaciones frente a la hegemonía de quien quiere detentar una determinada perspectiva, que es siempre aquel que posee el poder: los «vencedores» de la historia ${ }^{39}$. El Comité Invisible ${ }^{40}$ habla de recodificar y hackear los flujos del poder infraestructural y horizontal ${ }^{41}$ (paradigma Google) que nos atraviesan; esto es: transformar la acción revolucionaria en un devenir-hacker-colectivo ${ }^{42}$ que permita sustraernos a la lógica de la dominación de las infraestructuras logísticas del nuevo paradigma del poder (que ya no reside en los parlamentos, sino en Sillicon Valley). La figura del hacker no es casual; no en vano este «sujeto» es precisamente quien conoce cómo opera el nuevo paradigma del poder logístico y quien puede reconfigurar el código al servicio de la emancipación. No se trata, por supuesto, de ensalzar la figura del hacker como sujeto revolucionario del siglo XXI, sino en que cada uno de los individuos tome la (revolucionaria) decisión de apoderarse de los saberes cuyo desconocimiento perpetúa la dominación cibernética. La revolución, de este modo, toma la forma del sabotaje, pero también de la reapropiación de saberes que son poderes ${ }^{43}$.

En definitiva, ser revolucionarios hoy puede que signifique no serlo en absoluto, en el sentido de no esgrimir relatos emancipatorios que, en definitiva, se mantengan en la lógica de dominación de la metafísica. Ser revolucionarios puede que signifique ser

39 «Pero allí donde nada (más) acontece o puede acontecer, del Ser como tal ya no queda nada, según la definición nietzscheana de nihilismo. Lo que para nosotros y para (nuestro) Heidegger significa que, con la ausencia del evento, esto es, del Ser, no habría ya diferencia, el orden existente sería el único definitivamente verdadero y no habría ya ningún horizonte alternativo que oponerle. (...) Para nuestro presente, esto significa oponerse con todas las fuerzas a quien niega la diferencia, el conflicto, el cambio. A quien olvida y quiere que nos olvidemos del Ser mismo.» (G. Vattimo, De la realidad, op.cit. p.143) (La cursiva es mía)

40 No casualmente, el nombre de la revista que editó este colectivo entre 1999 y 2001 (Tiqqun) toma su nombre de la Cábala (tikkun), término que significa redención, reparación (análogo, según Gershom Scholem a la apocatábasis cristiana, como restitutio ad integrum) y que es uno de los pilares de la teoría de la revolución de Benjamin. Véase M. Löwy, op.cit., p.108 y ss.

41 Frente al paradigma vertical, propio de las sociedades modernas pre-informáticas. Véase el ensayo «Fuck off Google» en Comité Invisible, A nuestros amigos, ed. Pepitas de calabaza, Logroño, 2016.

42 Véase Amador Savater: Reabrir la cuestión revolucionara (lectura del comité invisible) en: www.eldiario. es [ http://www.eldiario.es/interferencias/comite_invisible-revolucion_6_348975119.html] (Publicado el 23 de enero de 2015 y consultado el 7 de Junio de 2016)

43 En la misma línea que el anterior artículo véase: A.Savater, La revolución como problema técnico: de Curzio Malaparte al Comité Inivisible, en www.eldiario.es [http://www.eldiario.es/interferencias/ Curzio_Malaparte-Comite_Invisible_6_447315274.html] (Publicado el 31 de noviembre de 2015 y consultado el 7 de Junio de 2016) 
opacos. Que los flujos terminen en nosotros. Espacios de oscuridad. Interruptores siempre cerrados. Y una vez el flujo se interrumpa (el histórico, el informacional, el político-espectáculo), reconstruir el código con términos inasumibles para la «gran máquina». Crear una apertura para acontecimientos no programables, imprevisibles.

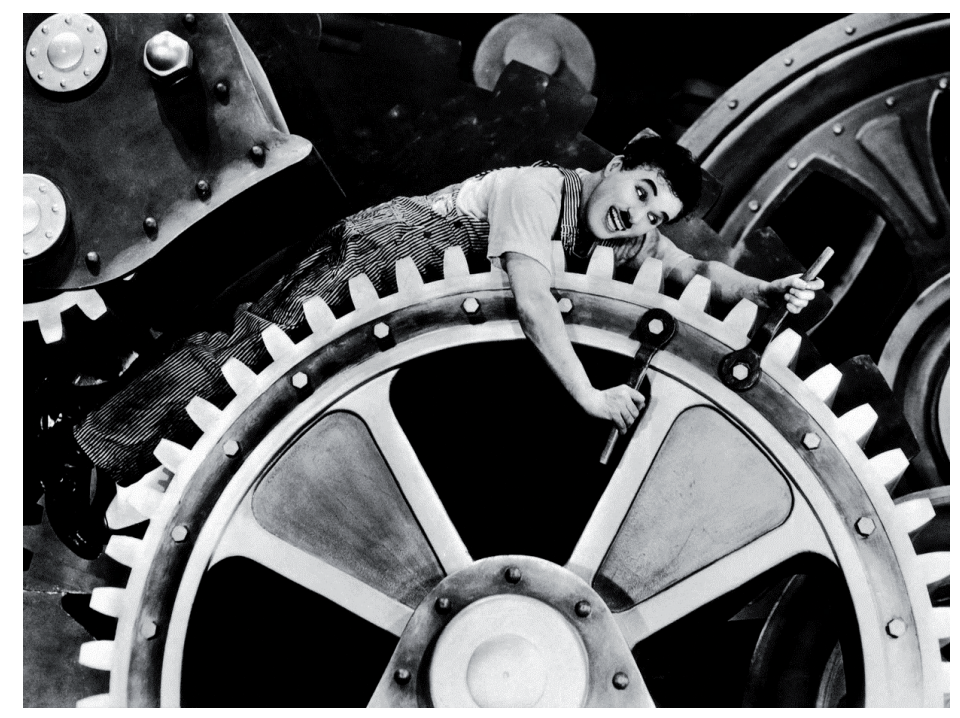

Figura 1

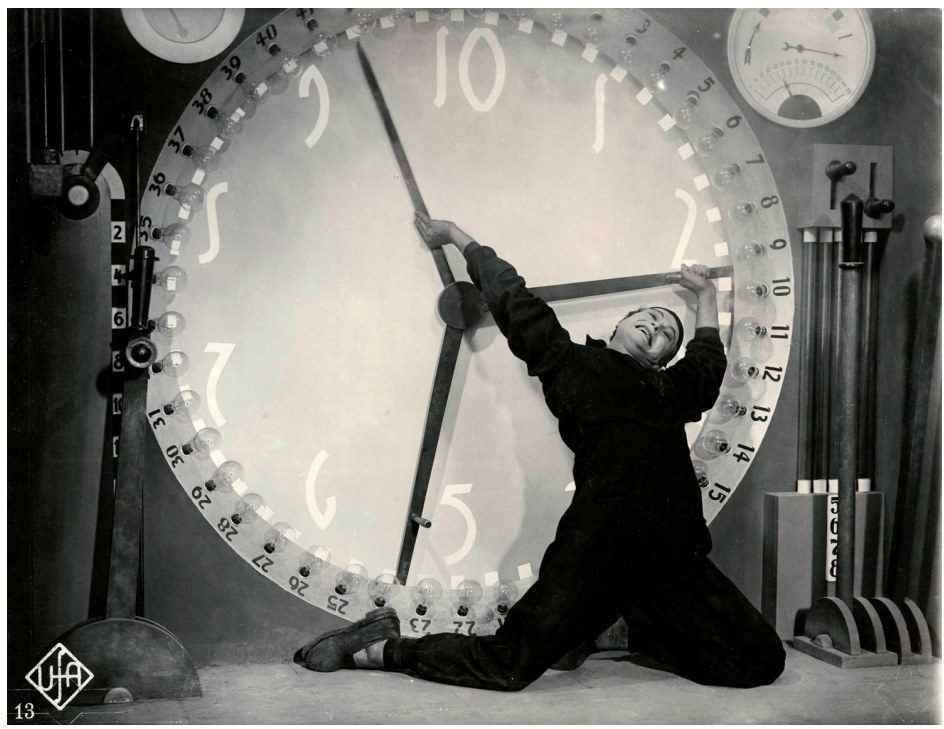

Figura 2 
Quiero pensar -y esta es mi apuesta pascaliana- que los «movimientos de las plazas», pese a haber sido prácticamente inocuos para el establishment político neoliberal, han supuesto un primer ensayo de estas nuevas revoluciones que ya no buscan la reorganización de la sociedad (imponiendo un nuevo régimen metafísico) sino la reconfiguración técnica de los mundos ${ }^{44}$; basadas en la interrupción y la opacidad -frente a la transparencia total de la cibernética- pero también en la creación de nuevos «encuentros» imprevisibles. Crear nuevos dialectos y multiplicar los conflictos de interpretación, allí donde una verdad o hegemonía quiera imponerse o mantenerse en un único lenguaje; en definitiva: allí donde se pretenda que «todo funcione» en detrimento del acontecimiento diferencial. En los intersticios nacidos de la interrupción de la gran maquinaria, en esos espacios de caos donde el tiempo homogéneo y vacío se ve suspendido, aparece kairós, el momento de la oportunidad. ¿Y quién sabe si, a través de esa fisura vislumbraremos cómo tímidamente, en la penumbra, sin trompetas ni cortejos triunfales, se abre quejumbrosa... «una pequeña puerta» ${ }^{45}$ ?

44 «Una perspectiva revolucionaria no se dirige ya a la reorganización de la sociedad sino a la configuración técnica de los mundos.» (Comité Invisible, op.cit. p.100)

45 En alusión al famoso fragmento final de las Tesis... de Benjamin: «Se sabe que a los judíos les estaba prohibido escrutar el futuro. En cambio la Torah y la plegaria les instruyen en la conmemoración. Esto desencantaba el futuro, al cual sucumben los que buscan información en los adivinos. Pero no por eso se convertía el futuro para los judíos en un tiempo homogéneo y vacío. Ya que cada segundo era en él la pequeña puerta por la que podía entrar el Mesías.» W. Benjamin, Discursos interrumpidos, op.cit. p.191 (La cursiva es mía) 